\title{
Tradução parcial e comentada do Convívio de Dante
}

\author{
Emanuel França de Brito*
}

Abstract: This work aims at presenting a partial translation of Dante Alighieri's Convivio and make explicit the reason for some choices made for the presented translation. It brings only the three first chapters from the first tome of Convivio (CV I I, II, III e IV). It attempts to justify these choices based on Busnelli's (1934; 1937), Vasoli's (1988), and Inglese's (2007) comments, besides having Ageno's critical edition (1995) as its textual basis. Morevover, it reflects about the use of certain vocabulary by authors who were contemporary with the text, such as Francesco Petrarca and Giovanni Boccaccio, also considering other texts by Dante, in their original version and in some of their most important translations to Portuguese.

Keywords: Translation; Dante Alighieri; Convivio.

Resumo: Este ensaio tem por objetivo apresentar uma tradução parcial do Convívio, de Dante Alighieri, e explicitar a razão de algumas das escolhas feitas para a tradução apresentada. Tem como recorte apenas os quatro primeiros capítulos do primeiro tratado da obra (CV I I, II, III e IV). Tenta-se justificar essas escolhas com base nos comentários de BUSNELLI (1934; 1937), VASOLI (1988) e INGLESE (2007), além de ter a edição crítica de AGENo (1995) como base textual. Ainda, reflete sobre o uso de certos vocábulos em autores contemporâneos ao texto, como Francesco Petrarca e Giovanni Boccaccio, considerando também outras obras de Dante, no original e em algumas de suas principais traduções para o português.

Palavras-chave: Tradução; Dante Alighieri; Convívio.

\footnotetext{
* Doutorando em Língua e Literatura Italiana pela FFLCH-USP, sob orientação do Prof. Dr. Maurício Santana Dias. Bolsista da Fundação de Amparo à Pesquisa do Estado de São Paulo. Email: emanuelbrito@usp.br.
} 
BRITo, E. F. Tradução parcial e comentada do Convívio de Dante

\section{Apresentação}

Convívio, assim intitulado pelo próprio Dante Alighieri (Cv I । 16), pode ser definido brevemente como uma obra filosófica na qual o poeta expõe conclusões de suas experiências intelectuais de juventude. Ali, o autor desenvolve, entre 1304 e 1307, anos em que estava no exílio, comentários em prosa sobre algumas de suas canções, compostas ainda na Florença natal tempos antes de sua expatriação. Eram 14 os tratados previstos por Dante para esse livro, mas a obra não foi completada e restaram somente quatro partes.

O primeiro tratado funciona como um preâmbulo ao livro. É iniciado com uma vigorosa citação aristotélica que afirma sermos todos naturalmente desejosos por saber, sendo esse desejo uma manifestação do instinto que conduz o homem a buscar pela sua própria perfeição, a qual é atingível apenas por meio do saber (CV | | 1). Nos outros três tratados, o autor desenvolve temas específicos para comentar suas canções: o segundo e 0 terceiro, expostos em 15 capítulos cada, são dedicados a explicitar o novo amor do poeta pela "belíssima e honestíssima ${ }^{1}$ filha do Imperador do universo, à qual Pitágoras deu o nome de Filosofia" (CV II XV 12), em substituição ao amor devotado à já morta Beatriz, sua musa da Vida Nova. O quarto tratado tem o dobro da dimensão dos dois primeiros e investiga sobre a verdadeira nobreza do homem, definida pelo poeta como "uma semente de felicidade colocada por Deus na alma bem disposta" (CV IV XX 9). Sobre o assunto dos outros 11 tratados restam apenas menções ao longo do texto, na maioria das vezes insuficientes para uma conclusão mais acertada.

Em se tratando de cultura italiana, é inegável o valor da obra de Dante na formação tanto de um idioma moderno quanto no "caráter nacional" de

\footnotetext{
${ }^{1}$ Sobre o valor que a palavra onesta pode ter na língua italiana dos séculos XIII e XIV, ver 0 que Contini relata a respeito da sua acepção latina (honestus, mesmo radical de honor, "honra") com o significado de "nobre para o decoro externo" (CONTINI 2001: 21-31).
} 
BRITO, E. F. Tradução parcial e comentada do Convívio de Dante

uma Itália ressurgida²; seja pela dimensão fundadora que a Comédia atingiu, seja pelo fato de o poeta ter traçado na obra latina De Vulgari Eloquentia uma espécie de mapa do "vulgar ilustre", a língua culta que almejava para os italianos. Nessa obra, após percorrer as línguas vernáculas italianas, tidas por ele como "naturais", Dante esboça uma língua ideal que até hoje é discutida nos círculos linguísticos sob o título de "A questão da língua italiana". É exatamente com esse idioma ainda em formação que fora escrito o Convívio, apresentando hoje uma grande complexidade àqueles que se propõem a lê-lo na sua língua original e justificando a sua reabilitação frente ao leitor contemporâneo brasileiro.

Não se tem, necessariamente, como princípio do texto aqui apresentado a ideia de que a tradução deva facilitar a vida de quem lê uma obra vertida para outra língua. 0 que se almeja é encurtar o caminho entre 0 público de língua portuguesa e a obra de Dante Alighieri, sem ignorar que a outra parte desse longo caminho precisa ser percorrida pelas pernas do próprio leitor.

Em se tratando de Dante, o abismo cultural e linguístico que nos separa hoje do contexto do autor é imenso. Seria uma ilusão pensar que a versão para língua portuguesa daria conta de toda a complexidade envolvida na ação de ler esse ou outro autor medieval de tamanha importância para o pensamento ocidental. Além disso, o próprio trabalho de tradução está sendo encarado como um processo de estudo, no qual se intenciona percorrer a fundo a obra do poeta florentino.

Tendo em mente que os sentimentos do homem atual se movem em outra tônica, Steiner (2004) ressalta a incapacidade de se ler hoje vários autores antigos de maneira compreensiva. Seria o caso de incluirmos Dante nessa lista? Pelo sim e pelo não, cabe à tradução procurar renovar o contexto do autor na tentativa de diminuir a distância temporal. Sendo assim, cada

\footnotetext{
${ }^{2}$ Apesar de bastante problemática a definição de um "caráter nacional", aqui se procura ressaltar a importância de Dante no séc. XIX, cenário de relevantes movimentos políticos que geraram a unificação da península italiana. Dessa unificação provém o atual Estado Italiano, que no ano de 2011 celebrou seu sesquicentenário. Ver DIONISOTTI 1999: 255-303.
} 
parágrafo do Convívio está sendo vertido para o português com a preocupação de dar vida nova a uma obra antiga, valorizando toda a sua riqueza linguística e filosófica. 0 esforço aqui vai empregado no sentido de manter o leitor em contato com um texto que dispõe do maior número de características do original, mas que está sendo apresentado em um português distante sete séculos da língua de Dante.

Não se almeja propor um texto que imponha uma interpretação definitiva do Convívio, porém é inevitável que a leitura do tradutor se afirme em certos momentos. 0 que se busca é preservar a identidade da obra - com suas possíveis ambiguidades e aberturas para variadas interpretações -, sinalizando para que o leitor vá ao encontro do escritor (SCHLEIERMACHER 2007 [1813]), o qual estará à sua espera no meio do percurso representado pelo tradutor.

A tradução parcial que aqui se apresenta é o resultado do primeiro esforço de trazer ao público de língua portuguesa em nova versão o texto do Convívio, de Dante Alighieri. Embora outras traduções já tenham sido propostas para o português, busca-se com esta oferecer um estudo aprofundado da obra, que junto a um aparato crítico, possa enriquecer os estudos medievalistas brasileiros. A importância que se dá a esse trabalho é pensando que Dante, na maior parte das vezes, é lembrado apenas pela sua principal obra, a Divina Comédia, por si só digna de grande louvor dada a sua magnitude poética, estética, filosófica, histórica etc.

Contudo, não se pode ignorar que antes de chegar à selva oscura, Dante tenha percorrido os importantes caminhos relatados no Convívio, e nas suas, assim chamadas, obras menores, percurso no qual o poeta pôde amadurecer muito do que relatou no seu principal poema. 


\section{O Convívio em tradução}

Tratado I, capítulo I

(1) Assim como diz o Filósofo ${ }^{3}$ no início da Primeira Filosofia, todos os homens por natureza desejam saber. A razão de que assim seja pode ser, [e] é, porque todas as coisas movidas pela providência da primeira natureza são inclináveis à sua própria perfeição. Desse modo, uma vez que a ciência é a última perfeição da nossa alma, na qual está a nossa última felicidade, estamos todos sujeitos, por natureza, a desejá-la.

(2) Na verdade, muitos são privados dessa mais nobre perfeição por diversas razões que, internamente ou externamente ao homem, o conduzem para longe do hábito de ciência. (3) Internamente ao homem podem existir dois defeitos e impedimentos: um no que se refere ao corpo, outro no que se refere à alma. No corpo, é quando as partes estão indevidamente dispostas, de modo que nada podem perceber, assim como os surdos, os mudos e seus similares. Na alma, é quando a malícia ali prevalece, fazendo-a seguir viciosos deleites pelos quais o homem recebe tanto engano que todas as coisas vilipendia.

(4) Externamente ao homem, duas razões podem semelhantemente ser consideradas, uma das quais induz à necessidade, a outra à preguiça. A primeira são os cuidados familiar e civil, que necessariamente detém para si a maioria dos homens, de modo que não podem permanecer no ócio da contemplação. A outra é a carência do lugar onde a pessoa nasceu e cresceu, que às vezes não apenas a priva de qualquer estudo, mas a deixa longe de pessoas estudiosas.

(5) Duas dessas razões - ou seja, a primeira [interna e a primeira] externa - não devem ser difamadas, mas sim relevadas e dignas de perdão. As

\footnotetext{
${ }^{3}$ Aristóteles, o Filósofo por antonomásia para Dante, nas primeiras linhas da Metafísica (I I 980a 1).
} 
BRITo, E. F. Tradução parcial e comentada do Convívio de Dante

outras duas, ainda que uma mais que a outra, são dignas de repúdio e de abominação.

(6) Examinando bem, pode-se ver claramente, portanto, que poucos são aqueles que podem atingir o hábito desejado por todos, e praticamente inumeráveis são os impedidos que vivem sempre famintos desse alimento. (7) Oh, benditos sejam aqueles poucos que se sentam à mesa onde se come o pão dos anjos ${ }^{4}$ ! Pobres daqueles que com as ovelhas compartilham o alimento!

(8) Mas, como todo homem é, por natureza, amigo de todo homem, e todo amigo se compadece da carência daquele que ama, aqueles que em tão alta mesa se alimentaram se voltam, não sem misericórdia, àqueles que veem comendo pasto e castanhas, alimento de animais. (9) E uma vez que a misericórdia é a mãe do benefício, os que sabem oferecem sempre generosamente a sua boa riqueza aos verdadeiros pobres, sendo como uma fonte viva cuja água refresca a sede natural que foi antes mencionada. (10) Portanto, eu - que não me sento à bendita mesa, mas que fugi do alimento da plebe, movido pela misericórdia, recolho aos pés daqueles que lá se sentam o que deles cai; e, sem esquecer de mim mesmo, conheço a mísera vida daqueles que atrás de mim deixei, pela doçura que sinto naquilo que pouco a pouco recolho - tenho algo reservado para os miseráveis que há algum tempo demonstrei aos seus olhos, pelo que os fiz intensamente desejosos. (11) E agora, querendo reuni-los à mesa, intenciono fazer um banquete geral com aquilo que a eles demonstrei e com o pão necessário a tal alimento, sem 0 qual não poderia ser comido por eles; e este banquete possui desse digno pão, tal alimento que eu aspiro [não] ser ministrado em vão ${ }^{5}$.

(12) Por esse motivo, não se sente quem estiver mal disposto com seus órgãos, quem não possui dente, língua ou paladar; nem mesmo o escravo dos

\footnotetext{
4 Metaforicamente posto como "sabedoria"; maná, que caiu dos céus para alimentar os hebreus no deserto (Bíblia, Salmos 77, 25). Também na obra de Dante em Purg. 13; Par. II 11; XII 82-84. La verace manna è il cibo divino, e non quello mondano (CHIAVACCI LEONARDI Par. 2005: 343).

${ }^{5}$ Para essa última frase, adoto a versão de Inglese (cotale vivanda), em detrimento de Ageno ( $c 0[n]$ tale vivanda; segundo essa comentadora, a versão adotada pertence ao arquétipo $\mathrm{X}$ e, por isso, é passível de correção. Para a complexa questão que aborda a falta de um texto autógrafo de Dante, do arquétipo e dos manuscritos do Convívio, ver AGENo 1995.
} 
BRITO, E. F. Tradução parcial e comentada do Convívio de Dante

vícios, porque o seu estômago está cheio de humores venenosos e contrários, sem nunca conservar nenhum alimento. (13) Mas, venha quem permaneceu na fome humana [por cuidados] familiar ou civil, e se sente a uma mesa com outros igualmente impedidos; aos seus pés, coloquem-se todos aqueles que se acomodaram por preguiça, pois não são dignos de mais alto assento; e ambos se sirvam do meu alimento com o pão que Ihes fará degustá-lo e digeri-lo.

(14) 0 alimento deste banquete será concebido de 14 maneiras, ou seja, [de] 14 canções, compostas tanto de amor quanto de virtude, e que sem o presente pão possuíam a sombra de uma obscuridade, de forma que a muitos a sua beleza era mais agradável que a sua bondade. (15) Mas esse pão, ou seja, a presente exposição, será a luz que fará aparente todas as cores dos seus conceitos.

(16) E se na presente obra - que Convívio é intitulada, e desejo que o seja - se discorre mais virilmente que na Vida Nova, não tenho a intenção de diminuí-la em parte alguma, mas acima de tudo enriquecer aquela com esta, mostrando racionalmente como aquela foi férvida e apaixonada, ao que cabe a esta ser moderada e viril. (17) Porque convêm dizer e agir de forma diferente em cada idade, uma vez que certos costumes são idôneos e louváveis em uma idade, mas inadequados e reprováveis em outra, como será mostrada adiante, no quarto tratado deste livro, com uma razão adequada. Enquanto na obra anterior eu falei na entrada da minha juventude, nesta posterior o faço tendo essa ${ }^{6}$ já se passado.

(18) E uma vez que a minha verdadeira intenção era outra que não aquela que mostram externamente as citadas canções, intento mostrá-las por exposição alegórica, seguida da história literal racionalizada, de modo que tanto uma razão quanto outra dará sabor àqueles que a este jantar são convidados.

(19) A todos esses peço que se o banquete não for tão esplêndido como cabe esperar pela sua invocação, que não atribuam todo defeito ao meu

\footnotetext{
${ }^{6}$ Ambiguidade do original, pois não se sabe o que se passou, a entrada ou a juventude.
} 
BRITo, E. F. Tradução parcial e comentada do Convívio de Dante

desejo, mas sim à minha capacidade, porque a minha vontade é aqui seguidora de completa e estimada generosidade.

I, II

(1) No início de todo banquete bem concebido é comum que os serviçais peguem o pão oferecido e purifiquem-no de qualquer mancha. De forma que eu, [que] no presente escrito ocupo essa posição, de duas manchas primeiramente intenciono limpar esta exposição, que como pão se considera no meu provimento. (2) Uma é que falar de si mesmo não parece lícito, a outra é que falar expondo demasiadamente a fundo não parece racional. Assim, tanto o ilícito como o irracional, a faca do meu juízo purifica dessa forma:

(3) Os retóricos não concedem a ninguém falar sobre si mesmo sem uma real necessidade, e disso o homem se abstém, porque não se pode falar de alguém sem que o orador louve ou insulte aquele de quem fala; mas essas duas causas estão rudemente presentes na boca de todos ao falarem de si.

(4) E para esclarecer uma dúvida que aqui surge, digo que é pior insultar que louvar, ainda que ambas não devam ser feitas. A razão é que qualquer coisa que seja reprovável por si só é mais repugnante que aquela que o é por acidente. (5) Desprezar a si mesmo é reprovável por si só, porque o homem deve contar intimamente ao amigo o seu defeito, e nada é mais amigo que ele a si mesmo. Desse modo, deve se autorrepreender e chorar os seus defeitos na câmara dos seus pensamentos, e não abertamente. (6) Além disso, não é por não poder e nem por não saber se comportar que o homem é depreciado, mas sim por não querer; porque é no querer e no não querer pessoal que se julgam a malícia e a bondade. Por isso, quem repudia a si mesmo atesta conhecer o seu defeito, atesta não ser bom, e por esse motivo, deve, por si só, deixar de falar de si com reprovação. (7) Deve-se evitar louvar a si mesmo assim como a um mal acidental, pois não se pode louvar sem que esse louvor não se torne principalmente uma ofensa maior: é um louvor na superfície das palavras, mas é uma ofensa se investigadas a fundo, porque [as] 
BRITO, E. F. Tradução parcial e comentada do Convívio de Dante

palavras são feitas para mostrar o que não se sabe, de forma que quem louva a si mesmo mostra que não acredita ser bem estimado. Isso não acontece sem que haja uma consciência culpada, que se revela ao louvar a si mesmo e, por se revelar, insulta a si mesmo.

(8) E, ainda, o autolouvor e o autoinsulto devem ser evitados por uma mesma razão: trata-se de fazer falso testemunho, uma vez que não existe homem que seja verdadeiro e justo avaliador de si mesmo, pois o amor próprio nos engana. (9) Nesse sentido, para um autojulgamento, todos possuem as medidas do falso mercador, que compra com uma e vende com outra. Todos medem as suas más ações com uma grande medida, e as boas com uma pequena medida, de modo que o número, a quantidade e o peso do bem apareçam mais que se tivessem sido avaliados com a justa medida, assim como as medidas do mal aparecem menos. (10) Por isso, quem fala de si com louvor ou desprezo mente sobre o que fala ou mente sobre o seu conceito, possuindo, portanto, as duas falsidades.

(11) Portanto, uma vez que aceitar é confessar, quem louva ou insulta alguém diante de sua face comete uma ofensa, porque essa pessoa não pode aceitar e nem negar sem cair na culpa de louvar-se ou de insultar-se. Salve-se aqui o caso da devida correção, que não pode se dar sem o repúdio da falha que se quer corrigir; e salve-se também o caso de devida honra e exaltação, 0 qual não é possível sem fazer menção das obras virtuosas ou das dignidades adquiridas virtuosamente.

(12) Voltando à principal questão, digo [que], como se falou anteriormente, havendo razões necessárias, o falar de si é, na verdade, concedido. E entre outras necessárias, duas razões são mais evidentes. (13) Uma é quando não se pode afastar uma grande infâmia ou perigo sem falar de si. Nesse caso, então, é concedido, porque entre dois [maus] caminhos, pegar o "menos pior" é como pegar um bom. Essa foi a necessidade que moveu Boécio a falar de si mesmo, de forma que sob o pretexto de uma consolação desculpasse a perpétua infâmia do seu exílio ao mostrar sua injustiça, pois outro clemente não se apresentava. (14) A outra é quando, ao falar de si, 
BRITO, E. F. Tradução parcial e comentada do Convívio de Dante

proporciona um grande benefício a outra pessoa em forma de doutrina. Essa foi a razão que moveu Agostinho a falar de si nas suas Confissões, pois, pelo desenvolvimento da sua vida, foi de [menos] bom a bom, de bom a melhor, e de melhor a ótimo, dando-nos exemplo e doutrina, a qual não se podia receber por [outro] testemunho tão verdadeiro. (15) Portanto, se essas duas razões me justificavam, o pão do meu comentário está suficientemente purificado da sua primeira mancha. Move-me o temor da infâmia, e move-me o desejo de fornecer uma doutrina, o que outros na verdade não podem fornecer. (16) Temo a infâmia de ter seguido tanta paixão, como quem lê as nomeadas canções pode conceber que eu sou por ela dominado; infâmia que se afasta inteiramente ao tratar de mim aqui, mostrando que não a paixão, mas a virtude foi a razão que me demoveu. (17) Tenho a intenção de mostrar também o seu verdadeiro conceito, podendo alguém não vê-lo se eu não 0 revelo, pois está escondido sob a figura da alegoria. Isso não apenas dará um bom contentamento ao ouvido, mas um sutil ensinamento para assim se expressar e para assim interpretar escritos de outros.

I, iii

(1) Digno de forte repreensão é aquilo que, concebido para eliminar algum defeito, induz ao defeito por si mesmo, assim como se alguém tivesse sido mandado a separar uma briga e, antes de separá-la, começasse outra. (2) E como o meu pão está purificado por um lado, me convém purificá-lo por outro, de forma a fugir dessa repreensão. Por isso, o meu escrito, que comentário pode se dizer, é concebido para eliminar o defeito das canções antes citadas, e isso em si já seja talvez um pouco difícil em algum momento. Mas, tal dificuldade é aqui empregada para se evitar um defeito ainda maior, e não por ignorância.

(3) Ah, quem dera fosse do agrado do arranjador do universo que a razão da minha justificativa nunca tivesse existido! Assim, nem outros teriam cometido uma falha contra mim, nem eu teria sofrido injustamente a pena, 
BRITO, E. F. Tradução parcial e comentada do Convívio de Dante

digo, de exílio e de pobreza. (4) Depois de ter sido do agrado dos cidadãos da mais bela e famosa filha de Roma, Florença, de me jogar para fora de seu doce seio - no qual nasci e fui nutrido até o ápice da minha vida, e no qual, com a sua boa paz, desejo de todo o coração repousar o ânimo cansado e terminar o tempo que me é dado -, fui por quase todas as partes em que essa língua se estende, peregrino, quase mendigando, mostrando contra a minha vontade o flagelo do destino, que muitas vezes costuma ser atribuído injustamente ao flagelado. (5) Contudo, eu fui um barco sem vela e sem comando, levado a vários portos, fozes e praias pelo vento seco que exala a dolorosa pobreza; apareci aos olhos de muitos que, talvez por alguma fama, de outra forma me haviam imaginado, à vista dos quais não somente a minha pessoa se acovardou, mas de menor valor se fizeram todas as minhas obras, tanto as já feitas como aquelas ainda por fazer. (6) A razão pela qual isso acontece - não só a mim, mas a todos - convém aqui tocar brevemente: primeiro, porque a fama se estende para além da verdade; depois, porque a presença se diminui para aquém da verdade.

(7) A boa fama, na maioria das vezes, [é] gerada pela boa ação na mente do amigo e por ela, primeiramente, vem à luz; porque a mente do inimigo, ainda que receba a sua semente, não a concebe. (8) Essa mente que primeiramente a dá à luz - seja para adornar mais o seu presente, seja pela bondade do amigo que o recebe - não se detém aos termos da verdade, mas os extrapola. E quando os extrapola para ornamentar aquilo que diz, fala contra a sua consciência; mas quando é o excesso de bondade que os faz extrapolar, não fala contra ela. (9) A segunda mente que a recebe não se contenta somente com a ampliação da primeira, mas procura adornar a sua repetição, como se fosse de sua criação. Assim, por esse motivo e pelo engano que recebe da bondade que nela foi gerada, torna a boa fama mais ampla que quando a recebeu, [em] conformidade e em desconformidade de consciência como a primeira. A terceira mente receptora e a quarta repetem isso, ampliando a boa fama até o infinito. (10) Da mesma forma, projetando as mencionadas razões às suas contrárias, pode-se ver a razão da infâmia, que 
BRITo, E. F. Tradução parcial e comentada do Convívio de Dante

semelhantemente se engrandece. Por isso, Virgílio diz no quarto livro da Eneida que a fama vive para ser móvel e adquire grandeza ao andar. (11) Portanto, quem quiser pode ver abertamente que a imagem gerada só por fama, seja ela qual for, é sempre mais ampla que a coisa imaginada no seu verdadeiro estado.

I, iv

(1) Tendo sido mostrada anteriormente [a] razão pela qual a fama dilata o bem e o mal para além da verdadeira medida, resta para este capítulo mostrar as razões que fazem ver porque a presença, por oposição, se diminui; e uma vez mostradas, chega-se facilmente ao principal propósito, ou seja, o da justificativa dada antes.

(2) Portanto, por três razões a presença diminui o valor de uma pessoa: uma delas é a imaturidade, não me refiro à idade, mas ao ânimo; a segunda é a inveja, ambas correspondentes ao crítico; a terceira é a impureza humana, a qual corresponde ao criticado.

(3) A primeira pode-se brevemente assim retratar: a maior parte dos homens vive de acordo com os sentidos e não com a razão, como crianças; esses tais não conhecem as coisas se não simplesmente por fora e não veem a bondade das coisas, concebida para um fim próprio, porque mantêm fechados os olhos da razão, os quais penetram até ver esse fim. Desse modo, veem rapidamente tudo o que podem e julgam de acordo com a sua visão. (4) E já que algumas opiniões sobre a reputação al heia se formam por ouvir dizer - das quais o juízo imperfeito discorda estando em sua presença, pois não julga de acordo com a razão, mas somente de acordo com o sentido -, esses presumem ser mentira o que antes tinham ouvido e desprezam a pessoa antes apreciada. (5) Desse modo, para esses que, ai de mim, são quase todos, a presença reduz tanto uma quanto outra qualidade. Esses, rapidamente estão ávidos e rapidamente saciados; frequentemente estão felizes e frequentemente 
BRITO, E. F. Tradução parcial e comentada do Convívio de Dante

tristes, seja por curtos prazeres ou tristezas; rapidamente são amigos e rapidamente inimigos; fazem tudo como crianças, sem o uso da razão.

(6) A segunda pode ser vista por essas razões: a igualdade é razão de inveja para os viciosos, e a inveja é razão de mau julgamento, já que não deixa a razão julgar a favor da coisa invejada, de forma que a potência julgadora se torna, portanto, o juiz que escuta apenas uma das partes. (7) Desse modo, quando esses tais veem a pessoa famosa imediatamente sentem inveja, pois veem membros e poderes equivalentes aos seus, e, pela excelência de tal pessoa, temem ser menos apreciados. (8) Esses não apenas julgam mal, movidos pela paixão, mas, difamando, fazem com que outros julguem mal. Por isso, para eles, a presença diminui o bem e o mal em cada um que Ihes é apresentado; e me refiro ao mal porque muitos, deleitando-se nas más operações, sentem inveja dos malfeitores.

(9) A terceira é a impureza humana, que aqui se considera em relação àquele que é julgado, se com ele existe certa familiaridade e diálogo. Em evidência disso, deve-se saber que o homem é em muitas partes manchado e, como diz Agostinho, nada é sem mácula. (10) Algumas vezes, o homem é manchado por uma paixão, à qual não sempre pode resistir; algumas vezes, é manchado por algum membro mal concebido; algumas vezes, é manchado por algum golpe do destino; e, algumas vezes, é manchado pela infâmia de parentes ou de alguém próximo. A fama não traz consigo tais coisas, mas sim a presença, que as revela pelo diálogo. (11) Essas manchas lançam uma sombra sobre a clareza da bondade, de modo que a fazem parecer menos clara e de menor valor. Esse é o motivo pelo qual todos os profetas são menos honrados em suas pátrias; esse é o motivo pelo qual o homem bom deve estar sempre em presença de poucos, e menos ainda com familiaridade, de forma que o seu nome seja conhecido, mas não desprezado. (12) Esse terceiro motivo pode se aplicar tanto para o mal como para o bem, se todos os termos do raciocínio se projetarem aos seus contrários. Por isso, se vê claramente que, pela imperfeição inerente ao homem, a presença diminui em todos 0 bem e o mal além do que requer a verdade. 
(13) Desse modo - uma vez que, como dito antes, eu me apresentei a quase todos os itálicos, tendo me tornado mais vil que a verdade requer, não somente àqueles aos quais a minha fama já havia chegado, mas para outros a quem as minhas obras sem dúvida perderam comigo 0 valor -, à presente obra me convém dar um pouco de peso com o mais alto estilo, fazendo-a parecer de maior autoridade.

(14) E que essa justificativa baste à força do meu comentário.

\section{Comentários à tradução}

Em um primeiro momento, tratando da escolha do título em português, considera-se importante manter a estreita relação que a língua italiana da obra original mantém com a língua portuguesa da obra de chegada, não só pela sonoridade do título que o autor escolheu para o seu tratado, mas também pelo significado que o termo abrange. Em português, assim como em italiano, "convívio" pode indicar um banquete ou a participação de pessoas em um banquete, como constatado pela sua etimologia latina (Houalss 2001): conviva -ae (substantivo), "convidado, companheiro de mesa"; convivium -ì (substantivo), "banquete, refeição em comum"; convivor -áris (adjetivo/ depoente), "dar um banquete ou ser convidado para ele"; e convivo -as (verbo), "banquetear em grupo". Além disso, tem-se a primeira acepção da palavra quando se refere ao contexto brasileiro, ou seja, "a ação de viver em família, com intimidade ou familiaridade", com origem também no latim com o verbo convitáre, que dá origem a convitare (italiano) e "convidar" (português).

Já nos primeiros capítulos da obra, o autor explicita a intenção prioritária do seu tratado filosófico, ou seja, de conduzir seus leitores ao conhecimento e à virtude ( $\mathrm{CV}$ I IX 7) e, para isso, apresenta o seu tratado como um alimento, como um pão a ser consumido por aqueles que buscam a sabedoria ( $C V$ I । 14); a mesma sabedoria que ele considera uma necessidade 
BRITo, E. F. Tradução parcial e comentada do Convívio de Dante

natural da alma humana ( $C v \mid$ I 1). Nesse sentido, a forma que Dante escolheu para apresentar e comentar o conteúdo da obra faz transparecer um tom de autoexposição que aproxima o autor do seu interlocutor. Ao falar de suas experiências de juventude, de suas reflexões e até de seus medos em certos momentos, o autor busca se mostrar sem máscaras no texto, criando uma espécie de identificação com o leitor que configura a intimidade entre aqueles que estão à mesa. Dessa forma, resolveu-se estabelecer como Convívio o título para a tradução em português, no qual se mantém a transparência com o título original e se preserva toda a familiaridade entre aqueles que convivem; nesse caso, o autor e seus interlocutores.

Contudo, vale ressaltar que em alguns momentos ao longo da tradução, principalmente nos primeiros capítulos ( $\mathrm{CV}$ | | 11; 14; 19; || 1), essa justificativa não se presta, já que nessas passagens o vocábulo escolhido para a tradução de convivio foi "banquete", considerando-se que em português tal vocábulo pode ser sinônimo de "convívio" (Houalss 2001). Visando propiciar uma leitura mais corrente do texto de chegada, escolheu-se recorrer a "banquete" porque a palavra se enquadra nas descrições feitas pelo autor, pois várias são as menções que Dante faz ao universo alimentar ligado ao da instrução intelectual, não sendo "convívio" tão automaticamente ligado a esse contexto. Essa referência à metáfora alimentar ocorre principalmente no capítulo de abertura da obra, como ao se remeter aos que não tiveram acesso ao saber como aqueles que "desse alimento continuam com fome" ( $\mathrm{Cv} \mid$ । 6); ao louvar aqueles poucos que se sentam à mesa onde o "pão dos anjos" é consumido ( $C V I, 7)$; ao constatar que por um ato de misericórdia os sábios devem ser como "fontes daquela água que refresca a sede natural" para os mais pobres ( $C \vee|| 9$ ); ao reconhecer-se humildemente entre os excluídos de tal mesa dos sábios, mas ao colocar-se ao pés daqueles por já ter "recusado 0 alimento das multidões" ( $C V \mid$ । 10); e, finalmente, ao apresentar como base do "alimento" oferecido aos seus leitores o referido "pão dos anjos" (CV I I 14). 
Seguindo a mesma direção que norteia a escolha do título, tem-se como intenção dar prioridade às acepções das palavras que mantiverem uma relação direta com algum termo do português, com a intenção de preservar, quando possível, uma transparência entre o texto de partida e o de chegada. Se a partir do vocábulo original puder ser localizada em português uma palavra semelhante e com a mesma origem, a essa será dada prioridade. Isso salvo quando o texto de chegada ficar sobrecarregado de termos obsoletos, como por exemplo no caso de seguace ( $C v$ I I 19), para a qual foi preferida a forma "seguidora" à pouco usada em português corrente "sequaz".

Considerando-se que distância temporal entre o texto de partida e o de chegada cria uma necessidade especial em relação aos vocábulos, que muitas vezes carecem do confronto entre autores da mesma época, chega-se às palavras de SCHLEIERMACHER:

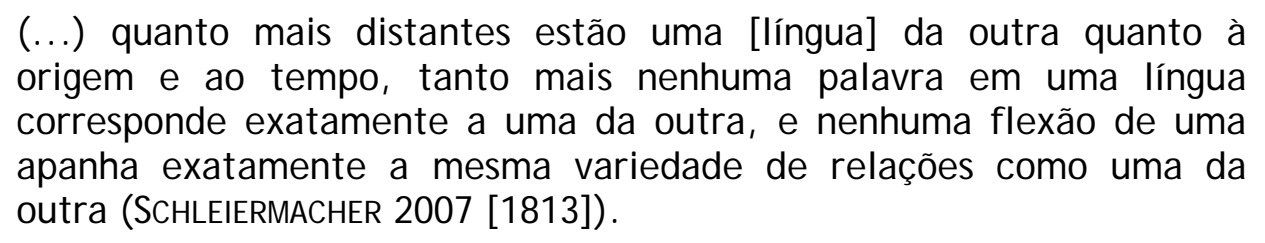

Veja-se, por exemplo, a forma como hoje se lê o substantivo grado; se anteposto à preposição in, pode ser ligado à noção de idoneidade ou à capacidade de se realizar uma ação (ZINGARELLI 2001). Contudo, a expressão in grado é tida diferentemente em Dante ( $C V$ I I 14). Primeiramente, consideremos grado em outra fase de sua escrita, onde se tem na Comédia:

Ma poi che pur al mondo fu rivolta contra suo grado e contra buona usanza, non fu dal vel del cor già mai disciolta.

(DANTE Paradiso III 115-117 - grifo meu).

Apesar de no mundo restaurada, contra a vontade e contra toda a usança, jamais Ihe foi do véu a alma privada. 
(Idem. Trad. Cristiano Martins - grifo meu).

Mas logo após que ao mundo regressada, contra seu grado e contra a boa usança, do véu do coração não foi livrada.

(Idem. Trad. Vasco Graça Moura - grifo meu).

No poema dantesco, o que se vê é o termo ligado à ideia de "vontade", traduzido pelo premiado poeta português Vasco Graça Moura ${ }^{7}$ como "grado", a qual pode ser considerada diacronicamente em português como uma palavra antiga para "vontade" (HouAlss 2001). Do mesmo verso tem-se a tradução do poeta brasileiro Cristiano Martins, que preferiu a ocorrência corriqueira do termo, traduzindo como simplesmente "vontade". Contudo, na passagem do Convívio parece ser mais denotado o sentido de "boa vontade", relacionada à "disposição favorável" com a qual as canções foram recebidas quando de suas composições:

La vivanda di questo convivio saràe di quattordici maniere ordinata, cioè [di] quattordici canzoni s̀ d'amor come di vertù materiate, le quali sanza lo presente pane aveano d'alcuna oscuritade ombra, sì che a molti loro bellezza più che loro bontade era in grado (Cv I I 14 - grifo meu).

0 alimento deste banquete será concebido de 14 maneiras, ou seja, [de] 14 canções, compostas tanto de amor quanto de virtude, e que sem o presente pão possuíam a sombra de uma obscuridade, de forma que a muitos a sua beleza era mais agradável que a sua bondade (Idem. Tradução e grifo meus).

Não pareceu oportuno, nesse caso, a tradução de in grado por expressões literais como "em grado", "em agrado" ou "em vontade", tampouco por aquela que foi inicialmente excluída relacionada à capacidade. Dessa forma, foi escolhido o adjetivo "agradável", por manter parte da sonoridade do original, mas principalmente por denotar um estado de espírito

\footnotetext{
${ }^{7}$ Prêmio Pessoa pela tradução de Vita Nuova e Divina Comédia (1995); Medalha de ouro da cidade de Florença, Itália (1998).
} 
BRITo, E. F. Tradução parcial e comentada do Convívio de Dante

benevolente daqueles que acolheram as canções, que naquele momento se mostravam mais belas do que benéficas do ponto de vista intelectual.

Pensando que todo texto tem as suas raízes no momento histórico em que foi concebido, "ler de maneira total significa recuperar ao máximo os valores e as intenções imediatas com as quais um dado discurso se apresenta de fato" (Steiner 2004). Com isso, considere-se a conjunção però, hoje essencialmente adversativa, mas que ligada a outros elementos pode indicar diferentes significados no italiano de Dante. Tem-se, por exemplo, però che, largamente usada no Convívio, como em:

Li quali priego tutti che se lo convivio non fosse tanto splendido quanto conviene alla sua grida, che non al mio volere ma alla mia facultade imputino ogni difetto: però che la mia voglia di compita e cara liberalitate è qui seguace (Cv II 19 - grifo meu).

A todos esses peço que se o banquete não for tão esplêndido como cabe esperar pela sua invocação, que não atribuam todo defeito ao meu desejo, mas sim à minha capacidade, porque a minha vontade é aqui seguidora de completa e estimada generosidade (Idem. Tradução e grifo meus).

Aqui, tem-se um uso causal da conjunção, assim como em muitos outros momentos da obra, como em "La seconda si vede per queste ragioni: che paritade nelli viziosi è cagione d'invidia, e invidia è cagione di mal giudicio, però che non lascia la ragione argomentare per la cosa invidiata $(\ldots)$ ", traduzido aqui como "A segunda se vê por estas razões: a igualdade é razão de invej a para os viciosos, e a inveja é razão de mau julgamento, já que não deixa a razão julgar a favor da coisa invejada (...)" (Cv I IV 6). Contudo, sendo ligada a outra conjunção, como a aditiva e, a adversativa però, pode denotar um tom conclusivo, dando origem a e però ou epperò. Isso se vê em "E però ad esso non s'assetti alcuno male de' suoi organi disposto (...)" traduzido por "Por esse motivo, não se sente quem estiver mal disposto com seus órgãos (...)" ( $\mathrm{Cv} \mid$ । 12); ou em "( ...) E però, con ciò sia cosa che 10 consentire è uno confessare", traduzido por "(...) Portanto, uma vez que 
aceitar é confessar" (Cv I I| 11). Da mesma forma conclusiva nota-se em Boccaccio, bem como em uma de suas traduções para o português feita por Torrieri Guimarães:

Madonna, pensando che io per voi possa omai sempre dire che io sia vivo, a quello guardando donde tôrre mi faceste, gran villania sarebbe la mia se io ogni cosa che a grado vi fosse non m'ingegnassi di fare; $\underline{e}$ però contentate il piacer vostro d'abbracciarmi e di baciarmi, ché io abbraccerò e bacerò voi vie più che volentieri (Boccacclo Decameron II 2).

- Mulher esplendorosa! Acho que poderei dizer para sempre que é por sua causa que ainda estou vivo! Contemplo a situação da qual você me tirou, e comparo-a com o estado em que você me deixou. Seria grande a minha vilania, se eu não fizesse todos os esforços para satisfazê-la em tudo o que for de seu agrado. Assim sendo, dê largas ao seu desejo, satisfazendo-o; abrace-me e beije-me, visto que eu a abraçarei e a beijarei com enorme e sincero entusiasmo (Idem. Trad. TORRIERI GUIMARÃES 1970).

Quanto ao ritmo do texto italiano, procura-se também manter a sonoridade de termos, ou parte dela, como no caso de tiene a vile sendo traduzido aqui por "vilipendia" ( $C v|| 3)$. Está claro que ao se fazer uma escolha para tradução usando o verbo "vilipendiar" do português não se trata de ter em mente o seu equivalente direto em italiano vilipendere com a sua acepção de "desprezar" (ZINGArelli 2001). Contudo, a locução em italiano tenere a vile pode manter o mesmo sentido do verbo "vilipendiar" ou "desprezar", como se observa também no poeta Petrarca em uma de suas mais famosas composições:

Da la matina a terza

di voi pensate, et vederete come

tien caro altrui che tien sé cosí vile.

(PETRARCA, Canzoniere [RERUm VULGaRIUM FRAGMENTA]

I CXXVIII 71-73 - grifo meu).

Matina a terça, cedo,

de vós pensai e então já vereis como

vos ama quem a si se tem por vil.

(Idem. Trad. Vasco Graça Moura - grifo meu). 
BRITo, E. F. Tradução parcial e comentada do Convívio de Dante

Pelo que se pode observar, o tradutor português preferiu manter a forma literal, que também mantém o sentido. Mas se considerada a equivalência semântica dos termos, nada se perde com o acréscimo do verbo "vilipendiar", já que se fosse escolhido um verbo como "desprezar", que também mantém o sentido do texto de partida, muito da sonoridade do original seria desperdiçado. Se mantido o verbo "vilipendiar", preservam-se as consoantes fricativa / v/ e a alveolar / / , apesar de não ser tão literal quanto a forma "tem por vil" de Graça Moura. De qualquer forma, o som labial da consoante / $\mathrm{p} /$ é acrescentado tanto à solução aqui proposta como aos versos de Graça Moura.

Ainda sobre a preservação sonora de certos vocábulos do Convívio, parece pertinente confrontar também a maneira como os mais hábeis tradutores integrais da Comédia para o português escolheram verter a obsoleta conjunção adversativa avegna che ${ }^{8}$, que irá aparecer muitas vezes no Convívio:

dette mi fuor di mia vita futura parole gravi, avvegna ch'io mi senta ben tetragono ai colpi di ventura; (DANTE Paradiso XVII 22-24 - grifo meu).

algo de minha vida ouvi futura que me preocupa, embora, estoicamente, eu possa suportar a desventura.

(Idem. Trad. Cristiano Martins - grifo meu).

ditas ouvi da vida a mim futura

palavras graves, mas meu ser se sustenta tetrágono tais golpes da ventura.

(Idem. Trad. Vasco Graça Moura - grifo meu).

\footnotetext{
${ }^{8}$ A grafia avvegna che ou avegna che dependerá da edição crítica tida como base. Para 0 texto da Comédia, adota-se a edição de A. M. Chiavacci Leonardi (2005), que por sua vez adota a de G. Petrocchi (La Commedia secondo I'antica vulgata. Florença: Le Lettere, 1994. 4 Vol.) e propõe algumas correções.
} 
BRITO, E. F. Tradução parcial e comentada do Convívio de Dante

Tendo em vista as duas traduções, parece que o poeta português foi mais feliz em manter o início do verso 23, já que o brasileiro começa uma transformação ainda no início no terceto, trocando as parole gravi por "algo". Com isso, perde-se o peso das palavras, o que Martins tenta compensar no verso seguinte com "que me preocupa". No entanto, ambos tiveram que reduzir avvegna ch'io a formas mais curtas para que o verso alterado não extrapolasse os limites do decassílabo (hendecassilabo italiano). Obviamente, tanto "embora" quanto "mas" mantêm a oposição característica das adversativas, porém, deixam escapar a repetição do som fricativo / v/ que avvegna ch'io conserva em relação a várias das palavras do terceto (fuor, vita, futura, gravi e ventura). Não é de se excluir que essas consoantes fricativas estejam envolvidas na harmonia musical do conjunto, quando a repetição de / V/ e / f/ sugerem tanto o flagelo das "palavras graves" ao corpo do poeta, quanto o esforço e a valentia na sua resistência "sólida" como um tetrágono.

É difícil sugerir uma solução melhor do que a encontrada pelos outros dois tradutores, principalmente porque a intenção desta análise é comentar uma tradução em prosa, na qual a preocupação com a contagem da silabação poética não está em primeiro plano. Fica mais simples criar uma solução que possa ultrapassar os limites das linhas, já que o texto em prosa não impõe barreira espaciais e sonoras tão nítidas quanto às impostas pelo verso. Sendo assim, para a tradução de avegna che em suas ocorrências no Convívio foi escolhido "ainda que", fazendo com que se aproxime mais do original e seja criada uma transparência entre os dois textos, mais uma vez, tanto pela sonoridade quanto pelo significado, mesmo que a referida fricativa tenha, com isso, se perdido. Como dito anteriormente, não se quer propor uma obra onde o tradutor seja invisível e o texto completamente transparente, mas é oportuno deixar que o leitor se aproxime das particularidades de forma e estilo do autor. Nesse intuito, chegou-se a: 
BRITo, E. F. Tradução parcial e comentada do Convívio de Dante

Le due di queste cagioni, cioè la prima dalla parte [di dentro e la prima dalla parte] di fuori, non sono da vituperare, ma da escusare e di perdono degne; le due altre, avegna che l'una più, sono degne di biasimo e d'abominazione (Cv I I 5 -grifo meu).

Duas dessas razões - ou seja, a primeira [interna e a primeira] externa - não devem ser difamadas, mas sim relevadas e dignas de perdão. As outras duas, ainda que uma mais que a outra, são dignas de repúdio e de abominação. (Idem. Tradução e grifo meus).

Mas, sendo o sentido do texto a prioridade na tradução, nem sempre será possível manter a relação de forma e sonoridade entre as línguas italiana e portuguesa, principalmente se considerada a distância temporal da obra de Dante aos dias de hoje. Com isso, imagina-se que até o fim do trabalho de tradução muitas serão as passagens que o leitor poderá confrontar ao original e constatar que aqui ou ali se perdeu parte do estilo de Dante. 0 que não se pretende de maneira nenhuma desvirtuar é o significado do texto dantesco, sendo em alguns momentos o ritmo e a musicalidade secundários. Espera-se, no entanto, que o processo de tradução da parte em prosa da obra possa ser um bom laboratório, e essa constatação de perda seja ínfima quando a comparação ao original seja feita com as canções da obra, onde o ritmo e a forma estão entre os elementos de maior importância.

No que diz respeito à sintaxe do texto de partida, a tradução apresentada procura manter e respeitar - quando possível - as relações de ordem, de concordância e de subordinação que o autor escolheu para o seu texto. Não simplesmente por se colocar em uma posição de inferioridade frente ao original, mas por crer que em se tratando de um texto tão afastado dos nossos tempos, é necessário que haja um estranhamento natural por parte do leitor para que se crie, ao longo da leitura, uma relação de distância temporal entre os contextos de escrita do original e leitura da tradução. Portanto, a intenção nesse sentido é de fazer presente o eco que a língua de Dante reverbera do latim, com construções ainda muito enraizadas na língua culta de então. Quer-se aqui evitar o que Berman chama de "racionalização" na linguagem da tradução ao se buscar uma ordem perfeita que não existe no 
BRITo, E. F. Tradução parcial e comentada do Convívio de Dante

original, pois segundo ele, "todo excesso de forma cristaliza a prosa do ensaio ou do romance, cuja 'imperfeição' é uma condição da possibilidade". Desse modo, a falta de ordem que o autor desejou para o seu texto tem a capacidade de penetrar em várias possibilidades lógicas de sua língua e "a racionalização destrói tudo isso em nome de uma pretensa 'impossibilidade'" (BERMAN 2007).

Nesse sentido, as relações tanto de ordem como de clareza do texto de chegada estão sendo avaliadas de acordo com aquilo que temos do texto de partida, de forma que o que se encontra distante de uma organização ideal ou que carece de transparência de significado possa se preservar como 0 autor assim o desejava; mas, não sem o filtro do tradutor. Dessa forma, com 0 auxílio de comentários críticos a serem fornecidos para acompanhar a tradução, indispensáveis em se tratando de Dante, caberá à percepção do leitor encontrar os equivalentes que o tradutor deixou à disposição com a abertura do texto. Veja-se o exemplo:

(...) acciò che la scienza è ultima perfezione della nostra anima, nella quale sta la nostra ultima felicitade, tutti naturalmente al suo desiderio semo subietti (DANTE CV I I 1).

(...) uma vez que a ciência é a última perfeição da nossa alma, na qual está a nossa última felicidade, estamos todos suj eitos, por natureza, a desejá-la (Idem. Tradução minha).

É de se considerar que o estranhamento pode ser expresso por uma linguagem em alguns momentos arcaizante. Contudo, mesmo esse estranhamento não deve ser em demasia, já que a proposta é trazer a obra a um leitor contemporâneo; e aqui entra o filtro do tradutor. Nesse sentido, em alguns momentos preferiu-se atualizar a sintaxe do texto de chegada para que a repulsa causada pela linguagem arcaica não seja exacerbada. Como no caso a seguir:

Dentro dall'uomo possono essere due difetti e impedi[men]ti: I'uno dalla parte del corpo, l'altro dalla parte dell'anima. Dalla parte del 
BRITO, E. F. Tradução parcial e comentada do Convívio de Dante

corpo è quando le parti sono indebitamente disposte, sì che nulla ricevere può, s̀ come sono sordi e muti e loro simili. Dalla parte dell'anima è quando la malizia vince in essa, si che si fa seguitatrice di viziose dilettazioni, nelle quali riceve tanto inganno che per quelle ogni cosa tiene a vile (DANTE CV I I 3 -grifos meus).

Internamente ao homem podem existir dois defeitos e impedimentos: um no que se refere ao corpo, outro no que se refere à alma. No corpo, é quando as partes estão indevidamente dispostas, de modo que nada podem perceber, assim como os surdos, os mudos e seus similares. Na alma, é quando a malícia ali prevalece, fazendo-a seguir viciosos deleites pelos quais o homem recebe tanto engano que todas as coisas vilipendia (Idem. Tradução e grifos meus).

No original, tem-se a locução "Internamente ao homem" como um advérbio de lugar onde podem existir os defeitos mencionados pelo autor logo no início do parágrafo. A ideia segue adiante, tendo-se "dois defeitos" ainda como sujeitos da frase, a não ser pela última consideração do parágrafo, onde o que antes fazia parte do advérbio de lugar (ao homem) passa a ser suj eito (o homem). Tornou-se, portanto, necessária a retomada de um sujeito que poderia estar inacessível ao leitor contemporâneo devido à grande distância que se encontrava do verbo com o qual concorda, característica típica da sintaxe latinizante. Não se trata de uma grande correção na sintaxe, mas apenas da recolocação de um elemento (sujeito) para conciliar melhor as partes e facilitar a compreensão.

Da mesma forma ocorre no exemplo a seguir, quando "a boa fama" precisou ser retomada para que os objetos dos verbos "tornar" e "ampliar" não faltassem ao texto, já que a sua menção se encontrava a dois parágrafos de distância (Cv I III 7).

La seconda mente che ciò riceve, non solamente alla dilatazione della prima sta contenta, ma 'I suo riportamento, si come qu[as]i suo effetto, procura d'adornare; e sì, che per questo fare e per lo 'nganno che riceve della caritate in lei generata, quella più ampia fa che a lei non vène, e [con] concordia e con discordia di conscienza come la prima. E questo fa la terza ricevitrice e la quarta, e così in infinito si dilata (DANTE CV I III 9 - grifos meus). 
BRITO, E. F. Tradução parcial e comentada do Convívio de Dante

\begin{abstract}
A segunda mente que a recebe, não se contenta somente com a ampliação da primeira, mas procura adornar a sua repetição, como se fosse de sua criação. Assim, por esse motivo e pelo engano que recebe da bondade que nela foi gerada, torna a boa fama mais ampla que quando a recebeu, [em] conformidade e em desconformidade de consciência como a primeira. A terceira mente receptora e a quarta repetem isso, ampliando a boa fama até 0 infinito (Idem. Tradução e grifos meus).
\end{abstract}

Mais um exemplo de reorganização moderada da frase é o que se expõe a seguir:

Dispregiare se medesimo è per sé biasimevole, però che all'amico dee
l'uomo lo suo difetto contare secretamente, e nullo è più amico che
l'uomo a sé: onde nella camera de' suoi pensieri se medesimo
riprendere dee e piangere li suoi difetti, e non palese (DANTE Cv I II 5 -
grifo meu).

Desprezar a si mesmo é reprovável por si só, porque o homem deve contar intimamente ao amigo o seu defeito, e nada é mais amigo que ele a si mesmo. Desse modo, deve se autorrepreender e chorar os seus defeitos na câmara dos seus pensamentos, e não abertamente (Idem. Tradução e grifo meus).

Tem-se no texto de partida uma organização que separa quase todos os elementos da frase das suas prováveis continuações, como o início feito com o complemento nominal seguido de parte do sintagma verbal e sujeito (a I'amico dee I'uomo); e com a desunião do sintagma verbal (dee [...] contare). Buscou-se uma disposição mais próxima do português, mas não que se tenha pensado em chegar ao extremo da ordem direta canônica "Sujeito - Verbo (ou sintagma verbal) - [advérbio] - Objeto - [complemento nominal]", onde teríamos: “( ...) o homem deve contar intimamente o seu defeito ao amigo", forma por demais domesticada. Com a intenção de equilibrar um pouco a frase ao leitor de hoje, chegou-se a uma forma onde se mantém uma parte das rupturas feitas pelo autor, mas sem que haja tantas quebras de sintaxe como as propostas no original. 
BRITo, E. F. Tradução parcial e comentada do Convívio de Dante

Para concluir, é importante dizer que por mais que se procure aqui evitar uma reinvenção dos sentidos e das formas do texto, é na reinterpretação da sua linguagem e dos seus significados que podemos absorver o legado que uma obra traz consigo. Por isso, a preocupação deste trabalho caminha na direção de renovar e retransmitir um conhecimento deixado, nesse caso, há mais de sete séculos, mas obviamente não sem excluir as marcas deixadas por este nosso tempo presente.

\section{Referências bibliográficas}

Alighierl, D. II Convivio ridotto a meglior lezione. Notas de G. Busnelli e G. Vandelli. Intr. de Michele Barbi. Florença: Le Monnier, 1934 (Vol.I); 1937 (Vol. II).

- Convivio. Notas de Cesare Vasoli e Domenico De Robertis. MilãoNápoles: Ricciardi, 1988.

. Il Convivio. Notas de Franca B. Ageno Florença: Le Lettere, 1995. Vol.

II, Tomo III.

. Convivio. Notas de Giorgio Inglese. 5ạ Ed. Milão: Rizzoli, 2007.

. La Divina Commedia: Inferno; Purgatório; Paradiso. Comentários de A. M. Chiavacci Leonardi. 1a Ed. Milão: Mondadori, 2005. 3 Vol.

. A Divina Comédia. Trad. Cristiano Martins. 8a Ed. Belo Horizonte: Ed. Itatiaia, 2006. [Tradução integral em verso].

. A Divina Comédia. Trad. Vasco Graça Moura. 2a Ed. São Paulo: Ed. Landmark, 2011. [Tradução integral em verso].

BíBLIA. Português. Bíblia de Jerusalém. Trad. Euclides M. Balancin [et al. ]. São Paulo: Paulus, 2003.

Berman, A. A tradução e a letra ou o albergue do longínquo. Trad. M-H. Catherine Torres [et al]. Rio de J aneiro: Nuplitt/ 7Letras, 2007.

BoÉCIO, A. M. S. La consolazione della filosofia. Trad. Ovidio Dallera; Christine Mohrmann. Milão: Rizzoli, 1995.

Boccaccio, G. Decameron. Comentários de Mario Marti e Elena Ceva Valla. 2a Edição. Milão: BUR, 2008.

. Decamerão. Trad. Torrieri Guimarães. São Paulo: Abril Cutural, 1970.

ContINI, G. Esercizio d'interpretazione sopra um sonetto di Dante. In: Un'idea di Dante. Saggi danteschi. 3a Edição. Turim: Einaldi, 2001. 
. Preliminari sulla lingua di Petrarca. In: Petrarca, F. Canzoniere [Rerum Vulgarium fragmenta]. Notas de Daniele Ponchiroli. Turim: Einaudi, 1992.

HouAlsS, A. Dicionário eletrônico da língua portuguesa. Versão 1.0. Rio de J aneiro: Instituto Antônio Houaiss/ Ed. Obj etiva, 2001.

Petrarca, F. Canzoniere [Rerum vulgarium fragmenta]. Notas de Daniele Ponchiroli. Turim: Einaudi, 1992.

. As Rimas de Petrarca. Trad. Vasco Graça Moura. Lisboa: Bertrand, 2003.

Schleiermacher, F. Sobre os diferentes métodos de traduzir. Trad. Celso Braida. Revista Princípios. J an/J un 2007. n. 21 v. 14. p. 233-365.

SIMonelLI, M. Convivio. In Enciclopedia Dantesca. 3a Edição. Roma: Istituto della Enciclopedia Italiana, 1996.

Steiner, G. Dopo Babele. Aspetti del linguaggio e della traduzione. Trad. Ruggero Bianchi; Claude Béguin. Milão: Garzanti, 2004.

Tommaseo, N.; BelliNI, B. Dizionario della lingua italiana. Roma-Turim-Nápoles: Unione Tipografico-Editrice, 1865.

ZingaRelLI, N. Lo Zingarelli minore. Vocabolario della lingua italiana. Edizione Terzo Milenio. Bolonha: Zanichelli, 2001. 